\title{
Jornalismo, Democracia e Educação: algumas reflexões sobre o Jornalismo Cívico
}

\author{
Marcus Antônio Assis Lima* \\ Jorge Cardoso Filho**
}

\begin{abstract}
Resumo
O artigo discute aspectos do movimento conhecido como Jornalismo Cívico a partir das transformações históricas pelas quais passa a prática jornalística. Enfatiza as relações estabelecidas entre as práticas jornalísticas e a democracia, de modo a demonstrar os papeis assumidos pelo Jornalismo em sociedades democráticas, e as articula metodologicamente às proposições de John Dewey sobre educação e vida pública, de modo que os jornalistas não apenas escrevam sobre práticas democráticas, mas pratiquem em seu ambiente de trabalho e eduquem seus leitores para a cidadania. Como conclusão, apresenta duas propostas para investigações posteriores em Jornalismo Cívico: adoção de novos definidores primários e desenvolvimento de enquadramentos em consonância com a agenda dos públicos.
\end{abstract}

Palavras chave: Jornalismo Cívico. Democracia. Educação. John Dewey. Práticas Jornalísticas.

Journalism, Democracy and Education: some reflections on civic journalism

Abstract

The article discusses aspects of the movement known as Civic Journalism from the perspective of the historical changes through which passes journalistic practices. It emphasizes the relations between democracy and journalistic practices

\footnotetext{
* Professor Adjunto do Departamento de Filosofia e Ciências Humanas, Universidade Estadual do Sudoeste da Bahia. Coordenador da Agência Experimental de Jornalismo Cívico, Vitória da Conquista-BA, Brasil. Doutor em Estudos Linguísticos pela UFMG. E-mail: prof.uesb@hotmail.com

** Professor Adjunto do Centro de Artes, Humanidades e Letras, Universidade Federal do Recôncavo da Bahia, Vitória da Conquista-BA, Brasil, e credenciado ao Programa de Pós-Graduação em Comunicação e Cultura Contemporâneas, Universidade Federal da Bahia, Salvador-BA, Brasil. Doutor em Comunicação pela UFMG. E-mail: cardosofilho.jorge@gmail.com
} 
in order to demonstrate the roles assumed by journalism in democratic societies, and the propositions articulated by John Dewey about education and public life, so that journalists not only write about democratic practices, but also practice in their workplace and educate their readers for citizenship. It concludes by presenting two proposals for further investigations into civic journalism: the adoption of new primary definers and development frames in line with the public agenda. Keywords: Civic Journalism. Democracy. Education. John Dewey. Journalistic Practices.

\section{Periodismo, Democracia e Educación: algunas reflexiones sobre periodismo cívico}

\section{Resumen}

El artículo analiza los aspectos del movimiento conocido como Periodismo Cívico a través de los cambios históricos cual pasa la práctica periodística. Hace hincapié en las relaciones entre la democracia y las prácticas periodísticas a fin de demostrar el papel asumido por el periodismo en las sociedades democráticas, y las proposiciones expresadas por John Dewey sobre la educación y la vida pública, para que los periodistas solamente escribán acerca de las prácticas democráticas, pero también desarrollen en sus locales de tranajo y educar a sus lectores para la ciudadanía. El texto se finda con la presentación de dos propuestas de nuevas investigaciones sobre periodismo cívico: la adopción de nuevos definidores primarios y los marcos de desarrollo en consonancia con la agenda del público. Palabras clave: Periodismo Cívico. Democracia. Educacion. John Dewey. Práctica Periodística.

\section{Introdução}

$\mathrm{J}$ ornalismo e democracia têm passando por momentos de crise. De um lado, o Jornalismo tem perdido a credibilidade, em parte pelo crescente uso do entretenimento como forma de atrair Mais público, mas também pelo distanciamento entre os conteúdos informativos e a vida cotidiana da maioria de seus leitores. A democracia, por sua vez, vem sendo atacada em várias partes do planeta, seja na censura chinesa à internet, nos 'empastelamentos' das emissoras de televisão e jornais venezuelanos ou nas declarações anti-imprensa do ex-presidente Lula. Mesmo assim, no mundo contemporâneo, podemos afirmar que o Jornalismo e a democracia são mutuamente dependentes. 


\section{JORNALISMO, DEMOCRACIA E EDUCAÇÃO}

Essa relação, à primeira vista bastante consensual, parece não estar completamente clara nas mentes dos jornalistas, dos políticos, dos cidadãos. Para os jornalistas, a democracia só é possível porque existe o Jornalismo para salvaguardá-la dos possíveis ataques antidemocráticos. Por sua vez, os políticos acreditam que o Jornalismo depende da democracia tendo em vista que esta garante o Estado de direito que permite a existência dos veículos de informação. No meio disso, os cidadãos enxergam o Jornalismo como algo exterior à vida cotidiana, algo que lhes apresenta friamente o presente em um amontoado de acontecimentos desprovidos de conexão com a vida comunitária.

Nesse contexto, um movimento jornalístico surgido nos Estados Unidos, no apagar dos anos 1980, conhecido como "Jornalismo Cívico" ou "Jornalismo Público", a depender do autor consultado, tem buscado resgatar as conexões entre os jornalistas e as comunidades que formam seus públicos. Para os fundadores do movimento, especialmente Jay Rosen, Davis Merritt e Arthur Charity, o Jornalismo Cívico ${ }^{1}$ baseia-se, principalmente, na premissa de que Jornalismo e democracia estão intrinsecamente conectados ou, mais precisamente, são mutuamente dependentes. Para eles, o Jornalismo tradicional tem fomentado uma lacuna na participação dos cidadãos na vida pública, afastando-os do processo democrático, especialmente no caso estadunidense, com o declínio da participação nas eleições políticas e, mais especificamente, contribuindo para o declínio da participação cívica na vida comunitária.

Dito de outra maneira, percebe-se um distanciamento entre os cidadãos e as instâncias governamentais e entre as organizações noticiosas e seus públicos. De modo a diminuir esse distanciamento, os defensores do Jornalismo Cívico acreditam que os jornalistas deveriam ter como sua principal e primeira responsabilidade o "estímulo ao engajamento cívico e à participação ativa no processo democrático" (HAAS, 2007, p.3). A premissa do Jornalismo Cívico, apesar de controversa, é de que a imprensa deve incentivar e, mais

\footnotetext{
${ }^{1}$ No Brasil, acreditamos que o termo 'Jornalismo Cívico', ou mesmo 'Jornalismo social', seja mais adequado, uma vez que 'Jornalismo público' pode levar a confusões com o Jornalismo praticado pelos veículos públicos de Comunicação.
}

Intercom - RBCC 
ainda, promover a qualidade da vida cívica ou pública, ao invés de apenas reportar ou queixar-se dela (GLASSER e LEE, 2002, p.203). Como sugere Jay Rosen (1995, p.54, negritos no original), os "jornalistas deveriam formar bem como informar o público".

Se o Jornalismo e a democracia são interdependentes e socialmente construídos, podemos arriscar dizer que essas instituições podem acabar, a menos que os jornalistas trabalhem em conjunto com os cidadãos na busca por soluções para os problemas que as comunidades enfrentam no dia-a-dia. Como podem as organizações informativas se reconectar com as comunidades alienadas da vida pública?

Esse artigo parte dessa questão e busca, através da revisão de uma teoria clássica da educação e das próprias teorias do Jornalismo, articular respostas que tornem possíveis a reconexão entre cidadão e vida pública, a partir da prática jornalística. Conclui que tal articulação é possível quando novos definidores primários são adotados e enquadramentos são desenvolvidos em consonância com a agenda dos púbicos.

\section{Relações entre Jornalismo e vida pública}

Interessante observar que esse movimento jornalístico que busca um retorno ao comunitarismo e formação dos cidadãos para a vida pública, parece retomar preceitos afirmados durante o processo de emergência de uma imprensa de opinião, no final do século 18. Trata-se daquele modelo de relação entre meios de Comunicação e vida política no qual a imprensa é uma espécie de instrumento a partir do qual os diversos atores políticos podem atuar. Wilson Gomes (2004), explica que esse modelo de relacionamento foi fundamental no contexto de combate ao Absolutismo, uma vez que era a imprensa de opinião que visibilizava (e criticava) determinadas ações da nobreza, trazendo-as para a vida dos cidadãos. Consequentemente, foi a partir daí que surgiram as bases para o estabelecimento de uma esfera pública, na qual os cidadãos podiam debater e construir publicamente suas opiniões.

Esse primeiro modelo de relacionamento entre imprensa e vida pública foi se transformando na medida em que a burguesia toma o 
poder político e institui um modelo democrático de governo. Como não era mais necessário criticar a natureza do regime de governo (afinal a maior parte das monarquias européias caíram no século 19) a imprensa passou a ser usada pelos grupos que não estavam exercendo o poder político para criticar o governo vigente - o que caracterizaria uma imprensa partidarista. Daí em diante, com a crescente profissionalização da imprensa e o surgimento de uma indústria da informação e do entretenimento, surgiu a necessidade de informação menos opinativa, mais imparcial, favorecendo o amadurecimento da concepção de notícia objetiva e informativa e, posteriormente, de notícias dramatizadas e fortemente emotivas, em busca de um público habituado a esse tipo de narrativa.

É justamente a partir da profissionalização da imprensa, por outro lado, que um campo efetivamente jornalístico começa a se constituir, na medida em que os profissionais passam a instituir padrões de ética e códigos de conduta, muitas vezes, avessos ao do campo político. Na medida em que esses códigos de conduta e regras de distribuição de prestígio se consolidam, o campo jornalístico ganha uma relativa autonomia, abrindo a possibilidade de explorar aspectos não tão ligados à vida pública mas também de aspectos ligados aos grupos empresariais, minoritários ou mesmo aspectos ligados aos (pré) conceitos arraigados numa determinada sociedade.

O principal problema é que quando a exploração de aspectos como esses (interesses empresariais, minoritários etc.) torna-se o padrão hegemônico, são necessárias alternativas que apontem as demais funções que o Jornalismo precisa desempenhar numa sociedade democrática -como o oferecimento de espaço para a pluralidade dos discursos sociais. Afinal, como o próprio Gomes (2004) sugere, tais formas de relacionamento entre Jornalismo e política não se excluem mutuamente, podendo mesmo ser encontrados concomitantemente num mesmo espaço público - jornais e revistas estruturados como grandes empresas de informação e usados como instrumento político são bastante comuns no Brasil, por exemplo.

Nesse sentido, parece importante desenvolver uma compreensão ampliada dessa relação entre Jornalismo e vida pública, a fim de não perder de vista determinadas transformações históricas que se configuram, nem tomá-las como fenômenos absolutamente no- 
vos. Estamos interessados em entender o Jornalismo Cívico como um movimento que retoma determinados parâmetros da relação entre constituição da vida pública e meios de Comunicação, em um contexto em que tanto os sistemas de governabilidade quanto a mídia parecem distantes da vida cotidiana dos cidadãos.

No âmbito dos sistemas de governabilidade porque muitos estudos já apontam a necessidade de promover uma retomada da democracia direta (sobretudo, via tecnologias digitais) em detrimento à democracia representativa. Os representantes eleitos teriam se afastado de tal modo dos ideais de suas bases que colocaram em dúvida a credibilidade do sistema representativo. No que se refere ao meios de Comunicação, tendo aqui a imprensa como foco, porque sua função de cão de guarda da sociedade civil tornou-se secundária frente à necessidade de geração de lucros com a informação, promovendo uma desconfiança semelhante no cidadão contemporâneo.

Parece importante, desse modo, destacar que, como se trata de uma configuração sócio-cultural específica, esse movimento de valorização de uma prática jornalística cívica vai depender do desenvolvimento de uma cultura política efetiva por parte dos cidadãos, que leve em consideração tanto os diferentes graus de informação e conhecimentos sobre a vida pública, as concepções e imagens disseminadas sobre a política, como também os modos destinados a assegurar a participação política (GOMES, 2005).

\section{Proposições de John Dewey}

Nascido em 1859, John Dewey devotou grande parte de sua vida a alertar as pessoas para a necessidade de se ampliar a democracia para as diversas esferas da vida cotidiana. Dewey foi um intelectual efetivamente dedicado a pensar como as experiências sociais (de naturezas diversas) podiam ser amplamente democratizadas. É nesse sentido que pretendemos abordar o pensamento de Dewey, especialmente aquele dos livros Educação e Democracia (1979) e The public $\mathfrak{E}$ its problems (1954), devido às implicações que suas posições representam tanto para o Jornalismo Cívico quanto para a tarefa de se preparar os futuros jornalistas. 
Para Dewey, a escola deveria ser pensada como uma comunidade em miniatura e com um currículo focado nos interesses naturais dos educandos. Vários relatos de experiências em Jornalismo Cívico parecem apontar para esse caminho, quer seja, a de que os jornalistas deveriam assumir um papel aparentado ao de um 'professor participativo', ou seja, ao invés de se perceberem como disseminadores de informações especializadas, os jornalistas deveriam se perceber como "facilitadores de uma interação pública". Essa preocupação é legítima, se verificarmos a resistência que os jornalistas que trabalham em empresas de informação, com alguma prática de Jornalismo Cívico, têm de se envolverem mais diretamente nas comunidades de abrangência dos jornais. Por exemplo, alguns estudos (ARANT; MEYER, 1998; DICKSON et al., 2001; JEFFRES et al., 1999; WEAVER et al., 2006) mostram que os jornalistas concordam que o foco de suas reportagens deve ser os problemas que afetam os cidadãos, que devem incorporar os pontos de vista sobre os problemas desses cidadãos em suas reportagens e que devem fornecer informações sobre as associações cívicas que lidam diretamente com esses problemas, mas não concordam que é responsabilidade dos jornais promover fóruns onde os cidadãos possam deliberar e chegar a possíveis soluções para os problemas, ou ajudarem os cidadãos a chegarem a um consenso sobre a melhor solução para determinado problema ou mesmo trabalharem diretamente com as organizações não governamentais de modo a ajudá-las a encontrarem e implantarem soluções para esses mesmos problemas.

De modo a atenuar esse distanciamento, os jornalistas deveriam promover o que Lemert (1981) denomina de "informação para a mobilização", ou seja, informações que mostrem como interagir com organizações cívicas que trabalham com problemas específicos, de modo que a esfera pública (midiática) e a sociedade civil (por intermédio de organizações cívicas) sejam vistas como estando em uma relação dialética explícita e de apoio mútuo. Haas (2007, p.47) defende que a responsabilidade primordial dos jornalistas deveria ser a de auxiliar a criar uma deliberação pública, através da criação e manutenção de uma esfera pública abrangente e aberta a qual todos os cidadãos tenham acesso e na 
qual todos os temas de interesse cívico e todas as opiniões possam ser articuladas, deliberadas e criticadas.

Para Dewey, toda Comunicação é educativa (1979, p.5), mais especificamente, podemos depreender a educação como uma "reconstrução ou reorganização da experiência que adere ao próprio significado da experiência, o qual incremente a capacidade de direcionar o curso da experiência subseqüente" (1979, p.86). Para ele, a educação representa um acúmulo para a reconstrução continuada da experiência: "A educação é para a vida social aquilo que a nutrição e a reprodução são para a vida fisiológica. A educação consiste primeiramente na transmissão pela Comunicação. A Comunicação é o processo da participação da experiência para que se torne patrimônio comum" (DEWEY, 1979, p.10).

Esse aspecto pode ser dito a respeito da reconstrução de comunidades inteiras através, por exemplo, dos esforços levados a cabo por experiências de Jornalismo Cívico². De maneira geral, as pesquisas mostram que os efeitos das práticas de Jornalismo Cívico são positivos para os cidadãos, em termos de conhecimentos, atitudes e comportamentos cívicos. Como descreve Haas (2007, p.54-56), em relação aos conhecimentos e atitudes cívicas, a cobertura de inspiração cívica tem ajudado os cidadãos a 1) se interessarem, adquirirem conhecimentos e preocuparem-se com os problemas e tópicos locais em anos de eleições; 2) a confiarem nos outros; 3 ) a possuírem vontade e capacidade de percepção para tomarem parte em atividades públicas para a resolução de problemas comunitários; 4) a adquirirem atitudes positivas em relação às organizações noticiosas participantes desses projetos. Thorson et al. (1997) descobriram que iniciativas de Jornalismo Cívico que visam envolver os cidadãos na resolução pública de

\footnotetext{
${ }^{2} \mathrm{Na}$ década de 1990, especialmente, vários projetos envolvendo comunidades no raio de abrangência dos periódicos foram lançados. Para ficarmos apenas em exemplos referentes a problemas raciais, podemos citar: a campanha "Question of Color", do Akron Beacon Journal, lançada em 1993 e vencedora do prêmio Pulitzer de serviço público em 1994. Outros exemplos são as campanhas "Side by Side", lançada em 1997 pelo Charlotte Observer; "Neighbor by Neighbor", de 2001, do jornal Cincinnati Enquirer; "The Color Chasm", de 1999, do Columbus Dispatch; "About Race", de 1998, do San Francisco Chronicle; e "The New Face of Minnesota", de 2000 (ver, para mais exemplos, HAAS, 2007; FORD, 2001).
} 
problemas comunitários são mais eficazes do que as iniciativas que têm por único objetivo envolver os cidadãos no debate público.

Assim, a educação deveria incentivar a aprendizagem pela prática e pelos hábitos adquiridos no contato com a "comunidade mais próxima" (neighborhood). Dewey (1979, p.107) defende que o objetivo da educação deve ser o de capacitar os indivíduos para que dêem continuidade a sua própria educação, ou seja, para ele, o objetivo último da educação é o crescimento social e individual. Tendo em vista essa posição de Dewey, de que a vida é desenvolvimento, e pensando mais especificamente na oposição entre objetivos internos e objetivos externos, também trabalhados por ele, no caso da 'educação para a mídia', isto é, a formação de jornalistas, por exemplo, um professor universitário pode, de acordo com as circunstâncias, restringir o ensino da escrita jornalística a uma revisão das regras gramaticais, admitindo que os estudantes não tenham tido contato com elas desde o ensino fundamental. Objetivos externos costumam ser mais rígidos. No geral, muito da educação vocacional e profissional, hoje, está centrada em objetivos externos e, na maioria das vezes, sem qualquer debate. $\mathrm{Na}$ formação de jornalistas, esses objetivos provêem de interesses mercadológicos e de regras de credibilidade. Uma crítica de Dewey ao modelo educacional de sua época, e ainda muito atual, dizia respeito à estreiteza de visão da educação vocacional.

Nesse sentido, a imersão social e tomada de consciência no reconhecimento do papel social que o profissional do Jornalismo, seja editor ou repórter, tem na inserção e participação dos cidadãos na vida pública, especialmente aqueles relegados ao segundo plano pelas escolhas dos temas e fontes pelo Jornalismo tradicional, deveria ser a tônica na formação desses profissionais. Também os professores dos cursos de Jornalismo precisam compreender esse papel, deixando de lado o treinamento de profissionais que visem atender as exigências organizacionais das empresas de informação, o que contribui para a precarização do trabalho e a pouca qualidade e utilidade dos conteúdos produzidos. Para além disso, como defende David Perry (2003, p.79), os professores de Jornalismo deveriam reorientar suas preocupações em educar para as técnicas da democracia deliberativa, inclusive para justificar, especialmente 
nas universidades públicas, os altos investimentos sociais que esses cursos demandam; aos alunos resta manter o sonho de que irão mudar o mundo.

O papel educativo que a prática do Jornalismo Cívico exige dos editores e repórteres pode ser assumido como um processo continuado de educação para a cidadania. No caso do ensino de Jornalismo, muito melhor que os jovens jornalistas possuam a capacidade de se adaptarem ao futuro do que possuir as qualidades mercadológicas exigidas para seus primeiros empregos.

Apesar de os praticantes do Jornalismo Cívico defenderem que a responsabilidade primordial do Jornalismo é promover a participação ativa dos cidadãos no processo democrático, eles ainda têm encontrado dificuldades em definir qual modelo de democracia os jornalistas deveriam ajudar a incrementar. Entretanto, as práticas atuais de Jornalismo Cívico, principalmente nos Estados Unidos, mas também em países como Dinamarca, Argentina, Finlândia, Suécia e Senegal, sugerem que as redações envolvidas em sua prática estão comprometidas com algum modelo de democracia deliberativa. Mais especificamente, estudos mostram que essas redações estão comprometidas com um modelo de democracia deliberativa onde as fontes oficiais são substituídas pelos cidadãos e onde os cidadãos participam ativamente nos assuntos comunitários locais. Em Dewey, essas eram preocupações recorrentes, ou seja, para ele, a educação deveria contribuir para uma melhoria na qualidade das comunidades e, por conseguinte, da sociedade. Mas, qual tipo de sociedade a educação deveria cultivar e promover? Dewey (1979, p.349) gostaria de visualizar uma "sociedade em que todas as pessoas se ocupem com alguma coisa que torne a vida das outras pessoas a mais digna de ser vivida”.

Haas (2007, p.29) propõe que, ao invés de assumir a existência de um público deliberativo, os jornalistas deveriam ajudar a tornar o público em um público deliberativo. Isso implica que o Jornalismo deveria contribuir para a manutenção de um espaço e de uma vida pública, encontrando maneiras nas quais os públicos possam interagir de maneira direta. Para isso, os jornalistas deveriam entender a opinião dos cidadãos como contribuições 
efetivas para a manutenção, e eventual mudança, do processo de deliberação pública. Indo mais além, de modo a garantir que o processo de deliberação pública seja aberto e inclusivo, os jornalistas deveriam repudiar as tentativas de desqualificação de certos cidadãos na participação igualitária, condenando os pontos de vista que excluem as opiniões divergentes.

De maneira geral, Haas (2007, p.35) defende que os jornalistas deveriam auxiliar na criação de uma deliberação pública, criando e sustentando uma esfera pública na qual todos os cidadãos tenham acesso e na qual todos os temas respeitantes aos cidadãos e todas as opiniões disponíveis possam ser articuladas, deliberadas e criticadas. De modo a facilitar a emergência de tal modelo de esfera pública, os jornalistas deveriam igualmente envolver os cidadãos no processo de construção da agenda midiática, bem como promover alguma forma de discurso público que integre a profundidade das interações face-a-face e as deliberações mediadas pelas mídias. Assim, os jornalistas deveriam ser encorajados a criarem uma esfera pública composta de múltiplos domínios discursivos nos quais os membros dos mais diversos grupos sociais poderiam articular e deliberar sobre seus interesses particulares entre eles próprios. Além disso, Haas (200, p.40) salienta, o Jornalismo Cívico não diz respeito apenas à criação das condições para uma deliberação genuinamente inclusiva e aberta, mas, para além disso, diz respeito à criação e manutenção das condições para a solução conjunta dos problemas, mesmo que os cidadãos discordem sobre quais problemas são politicamente mais relevantes.

Mas, como o Jornalismo poderia cultivar atitudes democráticas nos cidadãos se esses mesmos jornalistas desconhecem o trabalho, por exemplo, da comunidade onde vivem os leitores ou mesmo da comunidade científica, a qual oferece o modelo de democracia participativa? Ou seja, como promover a democracia se o ambiente de trabalho não é democrático? Em um artigo intitulado Consumidor ou cidadão? Estratégias para a qualidade do Jornalismo e da vida pública, (LIMA, 2009a), considerações são tecidas acerca da visão que os jornalistas possuem de seus públicos, isto é, a de que são consumidores de informação, em 
oposição à visão que deveriam ter: a de que eles merecem e querem ser tratados como cidadãos. Dewey defendia que a democracia deveria começar em casa, e que a casa da democracia era a comunidade. Claro que isso inclui o local de trabalho. Por exemplo, se os editores de determinada editoria noticiam apenas os aspectos frágeis da democracia, como podemos esperar que eles eduquem, adequadamente, os novos jornalistas? Do mesmo modo, muitos jornais adeptos da filosofia do Jornalismo Cívico continuam mantendo estruturas autoritárias de trabalho, talvez porque muitos jornalistas ainda mantenham atitudes tradicionalistas em relação ao seu trabalho.

Os veículos de informação que conseguiram alcançar muitos dos objetivos do Jornalismo Cívico precisaram, em algum momento, promover, principalmente, uma reestruturação fundamental na sala de redação e no próprio processo de elaboração das notícias (LIMA, 2009b). Nesse novo cenário, o modelo departamental tradicional de estrutura da sala de redação é solapado em favor de "equipes qualificadas circulares": essas equipes agrupam repórteres e editores em torno de questões comunitárias e não em torno dos pronunciamentos institucionais ou governamentais e seguem a agenda das comunidades ao invés da agenda dos burocratas. A reestruturação da sala de redação modificou a cultura da cobertura jornalística, por exemplo, no jornal State, da cidade de Columbia, na Carolina do Sul, nos Estados Unidos, levando- o a rejeitar reportagens focadas na cobertura dos "dois lados" em favor de coberturas que procuram um terreno comum e um conjunto de valores que permeiam as questões efetivas para a tomada de decisões no seio de uma comunidade, como mostra Scott Johnson (1998).

Dewey $(1979$, p.211) propõe uma resposta em relação ao tipo de educação vocacional que deveríamos incentivar: "Existe verdade no dizer que a educação deve primeiro ser humana e só depois profissional." Para ele, uma das principais deficiências do sistema educacional de seu tempo é que ele não cumpria o que seria, talvez, seu principal objetivo: o de criar atitudes científicas nos estudantes. Indo mais além, para ele, as pessoas deveriam aprender a analisar seus desejos e objetivos cientificamente. 


\section{O público e alguns problemas}

Se em Educação e Democracia (1979) Dewey nos apresenta possíveis soluções para os dilemas que afligem os professores de Jornalismo preocupados com a excessiva formação mercadológica dos futuros jornalistas, The public $\mathcal{E}$ its problems (1954) pode ser considerado, em muitos aspectos, a "Bíblia" do Jornalismo Cívico, mesmo que em outras obras, como em Liberalismo, liberdade e cultura (1970), uma tradução brasileira de distintos trabalhos do filósofo, ele também tenha dissecado a relação da democracia com a imprensa. É notório que The public $\mathcal{E}$ its problems foi escrito como resposta à visão pessimista de democracia descrita por Walter Lippmann, em Opinião Pública (2008).

Dewey compartilhava algumas das preocupações básicas de Lippmann: o nacionalismo, o auto-interesse econômico, a gestão da opinião pública e a capacidade de uma nova aliança perigosa entre os poderosos e os interesses da elite de negócios, o governo e as notícias. Mas, ao contrário de Lippmann, Dewey também estava preocupado com as divisões de classe que haviam sido provocadas pelo capitalismo industrial, o que ele sentia serem contrárias à ética da democracia. Para Dewey, a democracia era o reconhecimento da natureza essencialmente social e interdependente da existência humana. O núcleo da política democrática deveria ser o esforço para se criar as condições para que os indivíduos, em uma sociedade, desenvolvam a sua plena potencialidade. Ou seja, a democracia é uma ética, não uma máquina, e se estende até o local de trabalho. Dewey acreditava que a imprensa poderia ser reformada, e que deveria continuar a servir como elo vital entre o governo e o povo.

Assim, os estudantes de Jornalismo deveriam questionar em qual extensão a educação que recebem os vem encorajando a lidar com os públicos da mesma maneira que Dewey lidava com seus alunos, ou seja, de maneira a encorajá-los a adquirirem conhecimentos a partir das experiências, hábitos, habilidades de cada um. Pensando na imprensa, essa atitude sugere que os jornalistas deveriam participar de projetos públicos que ajudam a resolver os problemas que afetam os cidadãos, ou seja, que eles deveriam estar

Intercom - RBCC

São Paulo, v.35, n.2, p. 39-60, jul./dez. 2012

51 
empenhados em atividades cívicas de promoção de soluções para os problemas comunitários, ao invés de ficarem apenas fechados nos laboratórios de aprendizagem e salas de redação.

Em The public $\mathcal{E}$ its problems, Dewey começa a desenvolver suas ideias a partir de uma discussão sobre as várias teorias que procuram explicar o surgimento do Estado. Por exemplo, algumas dessas teorias entendem a formação do Estado como algo "instintivo" nos seres humanos. Dewey via essa discussão como uma visão equivocada que coloca as forças causais na primazia dessa formação, ao contrário de se ater nas consequências. Ao invés disso, ele sugere, haveria dois tipos de interação que ocorrem entre os seres humanos. Algumas são inteiramente privadas, como quando duas pessoas discutem sobre uma partida de futebol no caminho para o trabalho. Outras, como quando comerciantes planejam como monopolizar determinado mercado, têm consequências sobre os outros: "Quando conseqüências indiretas são reconhecidas e há um esforço para regulá-las, alguma coisa com traços de Estado começa a existir" (DEWEY, 1954, p.12). Quando consequências diretas ocorrem, dentro do grupo familiar, por exemplo, elas podem ser manipuladas dentro dos domicílios e não requerem medidas especiais. Com isso, podemos começar a encontrar pistas para o que ele entendia por público: "O público é composto por todos aqueles que são afetados pelas conseqüências indiretas das operações de tal forma consideradas necessárias para que essas conseqüências sejam sistematicamente atendidas" (DEWEY, 1954, p. 15-16). Além disso, "a marca externa óbvia da organização de um público ou de um Estado é, portanto, a existência de funcionários" (DEWEY, 1954, p.27). E mais: um "público articulado e operando através de agentes representativos é o Estado; não há Estado sem um governo, mas também não há um sem público" (DEWEY, 1954, p.34).

Em sua crítica às democracias do início do século 20, Dewey via na Comunicação o único remédio possível. O que faltava, ele pensava, eram ferramentas intelectuais para formar o público. Em um dos trechos mais acurados, ele escreveu:

Nós temos os instrumentos físicos para Comunicação como nunca antes. Os pensamentos e as aspirações congruentes com eles não são comunicados e, 


\section{JORNALISMO, DEMOCRACIA E EDUCAÇÃO}

portanto, não são comuns. Sem essa Comunicação o público permanecerá nas sombras, a procura de si próprio, mas abraçando seu desconhecimento mais que suas capacidades. Até que a Grande Sociedade se converta em Grande Comunidade, o Público permanecerá a parte. A Comunicação pode, sozinha, criar uma comunidade estendida. Nossa Babel não é a das línguas, mas a de signos e símbolos sem os quais a experiência compartilhada é impossível (DEWEY, 1954, p. 52).

A democracia, ele nos ensinou, não se aplica apenas ao Estado, mas, "para que ela se concretize ela deve afetar a todos os tipos de associações humanas, seja a família, a escola, a fábrica, a Igreja" (DEWEY, 1954, p. 53). Para ele, a democracia não é uma forma alternativa de associação humana, ela é a ideia mesmo de uma vida comunitária. Como escreve em Educação e Democracia:

A sociedade não só continua a existir pela transmissão, pela Comunicação, como também se pode perfeitamente dizer que ela existe na transmissão, na Comunicação. Há mais que um nexo verbal entre os termos comum, comunidade e Comunicação. As pessoas vivem em comunidade em virtude das coisas que têm em comum; e a Comunicação é o meio por que chegam a possuir coisas em comum (DEWEY, 1979, p.4. Itálicos no original).

Ele evitava equiparar a simples associação humana com a comunidade; aquela consiste em um pré-requisito para esta, mas não é uma garantia para sua instalação. Para ele, o conhecimento é o que tiraria o público das sombras, sendo que ele não é o resultado do contato isolado das mentes individuais com as coisas. Ao contrário, o conhecimento envolveria práticas sociais, conceitos, símbolos etc. Assim, Dewey defendia que a condição essencial para um público democraticamente organizado estava em um tipo de conhecimento que não existia a priori. "Não há como existir um público sem completa publicidade de todas as conseqüências que o afete" (DEWEY, 1954, p.68). O conhecimento, ele enfatizava, requer tanto o entendimento quanto a Comunicação. "A Comunicação dos resultados das demandas sociais é a mesma coisa que a formação da opinião pública" (DEWEY, 1954, p.76). A opinião pública, ele nos ensinou, envolve o julgamento por parte do público e diz respeito a assuntos públicos. Ela demanda constantes questionamentos "a fim de detectar as energias que estão em jogo

Intercom - RBCC

São Paulo, v.35, n.2, p. 39-60, jul./dez. 2012

53 
e deve ser rastreada através de uma intricada rede de interações de suas conseqüências" (DEWEY, 1954, p.77).

Muito apropriadamente, ele reconhecia que "o mais importante, em outras palavras, é aperfeiçoar os métodos e as condições do debate, da discussão e da persuasão" (DEWEY, 1954, p.88). Por exemplo, ele defendia a melhoria das técnicas jornalísticas, nos moldes do que hoje é chamado de reportagem interpretativa, na qual a notícia consiste tanto das descrições dos eventos bem como dos contextos históricos em que eles ocorrem. Já naquela época, ele criticava a tendência em se focar nos eventos chocantes, como os crimes e os acidentes, sem uma completa contextualização deles: "Sem coordenação e consecutividade, os eventos não são eventos, mas ocorrências simples, intrusões" (DEWEY, 1954, p.79). Há, aqui, algo implícito e profundo. Muitas notícias baseiam-se nos modelos mecanicistas de sensações ou impressões cruas que colidem com as mentes passivas dos leitores. Dewey atacava esse ponto de vista, encontrado no associacionismo de alguns filósofos britânicos empiricistas, como David Hume ${ }^{3}$. Em vez disso, Dewey argumenta que os jornalistas precisam se engajar em um processo de interpretação para evitar a criação de uma confusão, um zumbido (usando uma expressão emprestada de William James) na mente do público. Além disso, um dos efeitos da alfabetização nas condições existentes foi a criação de um grande número de pessoas com um apetite pela emoção momentânea, causada pelo impacto que estimulam nas terminações nervosas, mas cujas conexões com as funções cerebrais estão quebradas. Então, estimulação e excitação não são requisitos para a produção da inteligência (DEWEY, 1970, p.94).

Claro que tais objeções podem ser feitas, nos dias de hoje, não apenas em relação às notícias, mas também a certos programas de televisão. Antes de nos empenharmos em sentir pena dos habitantes das regiões rurais, antes da invenção dos dispositivos modernos para a circulação de informação, devemos lembrar que

\footnotetext{
${ }^{3} \mathrm{O}$ empirismo sensualista de Hume também pode ser encontrado em John Locke e David Berkeley. Grosso modo, consiste em afirmar que o conhecimento humano provém dos sentidos e que nada há no intelecto que antes não tenha passado pelos sentidos.
} 
eles sabiam mais sobre as coisas que afetavam suas vidas do que os moradores das cidades de hoje sabem sobre as causas de seus negócios (DEWEY, 1970, p.94).

Ele também criticou a influência do lucro no Jornalismo. "A montagem e apresentação de notícias seria uma coisa muito diferente se aos repórteres fosse permitido trabalhar livremente em seus verdadeiros interesses" (DEWEY, 1954, p.77), de modo que os progenitores da democracia, certamente não estavam errados em enfatizar a necessidade de uma imprensa livre e de escolas públicas para proporcionar condições favoráveis para a democracia. Mas, para eles, o inimigo da liberdade de imprensa era a censura e o controle oficial do governo; eles não previram que causas não-políticas poderiam restringir sua liberdade (DEWEY, 1970, p.92).

Grande parte da notícia deve consistir de resultados de investigação social. Segundo Dewey, a sociedade não precisa de um jornal que sirva apenas como uma edição diária de um jornal sociológico. Em vez disso, a apresentação da pesquisa social se torna crítica. Um Jornalismo eficaz poderia "quebrar a crosta de convencionalidade e rotina consciente" (DEWEY, 1954, p. 79). A democracia "terá sua consumação quando a informação social livre estiver indissociavelmente apegada à arte da Comunicação plena e emocionante"(DEWEY, 1954, p. 80).

\section{Duas propostas para o Jornalismo Cívico}

Expostas as proposições de Dewey, gostaríamos de sugerir uma espécie de programa conjunto de pesquisas para estudiosos interessados em fazer avançar a discussão e a prática desse Jornalismo orientado para as causas públicas. Não se trata de um programa institucionalizado, mas de ações e reflexões que podem ser efetivas a partir do desenvolvimento de determinadas hipóteses teóricas da pesquisa em media effects e também da pesquisa em Teorias do Jornalismo.

A primeira proposta pode ser exposta da seguinte forma: o Jornalismo Cívico precisa ouvir e publicizar os modos como os cidadãos comuns pensam sobre os problemas comuns, sobretudo os que os concernem diretamente. É preocupante o fato de, até 
os dias atuais, os chamados "definidores primários" (HALL et all, 1993) sejam tomados como únicos representantes autorizados a exporem publicamente afirmações sobre determinadas questões de interesse público. Na maioria da vezes, os cidadãos concernidos nesses problemas aparecem como que "tutelados" pela voz autorizada dos definidores primários e, portanto, apanhados numa posição de fragilidade - pois precisam de alguém autorizado para falar pelas suas demandas e reivindicações. Muitas vezes, essa "tutela" é dada aos representantes do governo, outras vezes ela é concedida aos especialistas, raramente um membro concernido é ouvido na mesma posição social de um representante governamental ou especialista.

Como se pode perceber, trata-se de uma proposta que coloca em xeque um pressuposto básico das Teorias do Jornalismo, a saber: a longevidade que os clássicos definidores primários ocupam na construção da narrativa jornalística. Como um discurso social inscrito histórico e culturalmente, as narrativas jornalísticas devem relocalizar as posições que os diferentes atores sociais ocupam em contextos diversos e, desse modo, reconhecer o papel que outros atores sociais exercem no sociedade contemporânea. É sintomático dessas reconfigurações, por exemplo, o crescimento das Organizações Não-Governamentais (ONG's) e dos movimentos sociais nos processos de participação e engajamento dos cidadãos. No atual contexto, membros desse movimentos e organizações devem ser também considerados como definidores primários.

Mais além, propomos que a categoria de definidores primários seja constantemente revisada e reformulada pelas dinâmicas sociais, das quais o Jornalismo faz parte. Nesse sentido, é possível entender de que maneira o Jornalismo Cívico reconfigura, tanta na prática quanto na teoria, os modos de conceber e encarar o Jornalismo.

O problema relativo à incorporação de novos definidores primários, nos contextos sociais e culturais particulares nos leva a um segundo problema e, consequentemente, a nossa segunda proposta. A necessidade de o cidadão comum ser incorporado como definidor primário precisa ser satisfeita sem recorrer a uma excessiva exploração das dimensões singulares da notícia, num movimento de dramatização e espetacularização. Afinal, o recurso 


\section{JORNALISMO, DEMOCRACIA E EDUCAÇÃO}

de personalizar determinado fato num exemplo a ser seguido ou numa história de vida é uma estratégia que tem contribuído muito mais para o desenvolvimento de um Jornalismo melodramático que para o Jornalismo Cívico (vide exemplos de cobertura de fatos como os casos Isabela Nardoni e Eliza Samúdio) e que reforça o lugar de fala autorizado de alguém exterior ao processo (o próprio jornalista). Trata-se de um problema de enquadramento ${ }^{4}$.

A proposta que fazemos, nesse sentido, é que o Jornalismo Cívico exponha as agendas de reivindicações desses cidadãos a partir dos enquadramentos próprios estabelecidos pelos movimentos e/ou organizações dos quais fazem parte. Enquadramentos que são, muitas vezes, incomuns à prática jornalística contemporânea, sobretudo porque os meios de Comunicação instituem seus próprios filtros e enquadramentos às demais agendas, de modo que, constantemente, um tema cuja origem é a agenda de um movimento social organizado, entra na agenda midiática a partir de um enquadramento definido por este último - um enquadramento mais acessível ao grande público.

Se a crítica de Dewey em relação à má-influência do lucro na atividade jornalística tem algum fundamento, ela reside no fato de que ao trabalhar livremente nos seus verdadeiros interesses (e não somente naqueles que geram lucros) o jornalista busca construir o enquadramento dos fatos sem "diluir" as contradições internas que são características daquele fenômeno. Ao passo que motivado apenas pelo lucro, a possibilidade de negligenciar determinadas contradições internas torna-se muito maior (ou mesmo desejável), uma vez que destacar-se-á aqueles elementos que motivam os lucros.

Pensamos que essas duas propostas podem ajudar tanto a construir uma prática mais efetiva de Jornalismo Cívico no Brasil, quanto uma reflexão metodologicamente mais rigorosa sobre os processos de transformação pelos quais o Jornalismo tem passado nos últimos 20 anos. Não é possível desvincular tais experiências de Jornalismo da desconfiança que os meios de Comunicação, de maneira geral, tem gozado. Esse clima de media mallaise em

\footnotetext{
${ }^{4}$ As pesquisas referentes ao framing analysis são extensas tanto nos Estados Unidos quanto no Brasil. Ver Goffman (1974), Entman (1993), Colling (2001), Porto (2004), Carvalho (2009).
} 
muito contribui para a reorganização do campo jornalístico, para o desejo de uma vida cotidiana mais livre e igualitária e o desejo de práticas políticas menos formais, mais plurais e democráticas.

\section{Considerações finais}

Os jornalistas, vamos dizer, deweyanos, têm como tarefa principal a promoção ou a socialização da inteligência social bem como ajudar aos públicos a identificar tal inteligência. Qualquer esperança de alcançar isso passa pela informação e pela publicidade dessa inteligência social. Resumindo, os jornalistas precisam prover as pessoas com os recursos necessários para uma efetiva democracia deliberativa. Para se alcançar isso, os jornalistas necessitam de "liberdade positiva" e não apenas da ausência de uma regulação formal por parte do Estado. Aqui, nos referimos especialmente ao fim da Lei de Imprensa no Brasil.

A constante revisão do conceito de definidores primários, bem como dos atores sociais que ocupam essa posição historicamente, e o uso de enquadramentos condizentes com a proposta desses públicos são proposta que apresentamos em dois sentidos, a saber: embasar, no campo teórico, as formulações feitas pelo Jornalismo Cívico e apresentar, no campo da prática jornalística, estratégias para não diluir as posições apresentadas por esses atores sociais nas rotinas de produção da notícia.

Reforçamos a ideia de que a educação, tanto dos futuros jornalistas quanto dos públicos, deve ser um processo de construção e transformação do conhecimento. Essa visão, assim, deve privilegiar estratégias que permitam a participação dos estudantes e gerem relações mais horizontais entre os eles e os professores. Dessa forma, os sujeitos se assumem como integrais e reconhecem que cada pessoa é diferente e, por isso, devemos respeitar os diversos ritmos de aprendizagem, estimulando o trabalho autônomo e mesmo ensinando a convivência com o outro.

\section{Referências}

ARANT, D.; MEYER, P. Public journalism and traditional journalism: a shift in values? Journal of Mass Media Ethics, v. 13, n. 4, p. 205-218, 1998. 


\section{JORNALISMO, DEMOCRACIA E EDUCAÇÃO}

CAREY, J. The press, public opinion, and public discourse. In: GLASSER, T.; SALMON, C. (Eds.). Public opinion and the communication of consent. New York Guilford, 1995. P. 373-402.

CARVALHO, C. A. Sobre limites e possibilidades do conceito de enquadramento jornalístico. Contemporanea, v. 7, n 2, p. 01-15, 2009.

CHARITY, A. Doing public journalism. New York:Guilford, 1995.

COLLING, Leandro. Agenda-setting e o framing: reafirmando os efeitos limitados. Revista FAMECOS, Porto Alegre, PUC-RS, n. 14, p. 88 - 101, 2001.

DEWEY, John. Liberalismo, liberdade e cultura. São Paulo: Edusp, 1970.

- Educação e Democracia: introdução à filosofia da educação.

4.ed.. São Paulo: Companhia Editora Nacional, 1979.

. The public and its problems. Chicago: Swallow Press, 1954.

DICKSON, T.; BRANDON, W.; TOPPING, E. "Editors, educators agree on outcomes but not goals". Newspaper Research Journal, 2001, 22 (4), 44-56.

ENTMAN, Robert. Framing: toward clarification of a fractured paradigm. Journal of Communication, New York, Autumn, v. 43, n. 4, p. 01 - 08, 1993.

FORD, P. Delving into the divide: a study of race in forty-five newsrooms. Washington, DC: Pew Center for Civic Journalism, 2001.

GLASSER, T.; LEE, F. Repositioning the newsroom: The American experience with public journalism. In: KUHN, R.; NEVEU, E. (eds.). Political journalism: new challenges, new practices. London: Routledge, 2002. P. 203-224.

GOFFMAN, Erving. Frame Analysis. New York: Harper \& Row, 1974.

GOMES, Wilson. Transformações da política na era da Comunicação de massa. São Paulo: Paulus, 2004.

- Internet e participação política em sociedade democráticas. Revista FAMECOS, Porto Alegre, PUC-RS, n. 27, p. 58 - 78, 2005.

HAAS, Tanni. The pursuit of public journalism: theory, practive, and criticism. New York, London: Routledge, 2007.

HALL, S, et al. A produção social das notícias: o "mugging nos Media. In: TRAQUINA, N. (org). Jornalismo: questões, teoria e estórias. Lisboa: Vega, 1993. p. $224-248$.

JEFFRES, L.; CUTIETTA, C.; LEE, J.; SEKERKA, L. "Differences of community newspaper goals and functions in large urban areas". Newspaper Research Journal, v. 20, n.3, p. 86-98, 1999.

Intercom - RBCC

São Paulo, v.35, n.2, p. 39-60, jul./dez. 2012 
JOHNSON, Scott. Public journalism and newsroom structure. The Columbia, S.C., Model. In: LAMBERTH, E.; MEYR, P.; THORSON, E. (Eds.). Assessing public journalism. Columbia, MO: University of Missouri Press, 1998. p. 123-142.

LIMA, Marcus A. Assis. Consumidor ou cidadão? Estratégias para a qualidade do Jornalismo e da vida pública. Biblioteca Online de Ciências da Comunicação. Covilhã, Portugal: Universidade da Beira Interior, 2009a. Disponível em < http://www.bocc.ubi.pt/pag/bocc-lima-seminario.pdf >. Acesso em: 27 fev. 2010.

LIMA, Marcus A. Assis. Filosofia do Jornalismo Cívico no jornal-laboratório 'Oficina de Notícias' da UESB: uma proposta de estrutura para a sala de redação. Trabalho apresentado no XII Encontro Nacional de Professores de Jornalismo, Belo Horizonte, 17 a 19 de abril de 2009b.

LIPPMANN, Walter. Opinião Pública. Petrópolis: Vozes, 2008.

LEMERT, J. Does mass communication change public opinion after all? Chicago: Nelson-Hall, 1981. 253p.

MERRITT, D. Public journalism and public life: Why telling the news is not enough. Mahwah, NJ: Lawrence Erlbaum, 1998.

PERRY, D. K. The roots of civic journalism: Darwin, Dewey, and Mead. Lanham, MD: University of America Press, 2003.

PORTO, Mauro. Enquadramentos da mídia e política. In: RUBIM, A.A. (Org.). Comunicação e política: conceitos e abordagens. Salvador: EdUFBA, 2004. p. $73-104$.

ROSEN, J. Foreword. In: CHARITY, A. Doing public journalism. New York: Guilford, 1995, p. v-vii.

ROSEN, J. Making journalism more public. Communication, v.12, n.2, p. 284, 1991.

TRAQUINA, Nelson. Teorias do Jornalismo: por que as notícias são como são. 2 ed. Florianópolis: Insular, 2005.

WEAVER, D.; BEAM, R.; BROWNLEE, B.; VOAKES, P.; WILHOIT, G.. The American journalist in the $21^{\text {st }}$ century: U.S. news people at the dawn of the $21^{\text {st }}$ century. Mahwah, NJ:Lawrence Erlbaum, 2006. 